American Journal of Pharmaceutical Education 2020; 84 (12) Article 8388.

\title{
COMMENTARY
}

\section{A Recent Pharmacy Graduate's Perspectives on Faculty and Course Evaluations}

\author{
Shelby Spencer Tungate, PharmD, MPA, ${ }^{a}$ Frank Romanelli, PharmD, MPH ${ }^{\text {b,c }}$ \\ ${ }^{a}$ University of North Carolina Medical Center, Chapel Hill, North Carolina \\ ${ }^{\mathrm{b}}$ University of Kentucky, College of Pharmacy, Lexington, Kentucky \\ ${ }^{c}$ Executive Associate Editor, American Journal of Pharmaceutical Education, Arlington, Virginia
}

Submitted September 10, 2020; accepted September 14, 2020; published December 2020.

\begin{abstract}
Written primarily by a recent pharmacy school graduate, this commentary aims to express the perceptions about pharmacy faculty members and course evaluations that students often hold. Colleges and schools of pharmacy use many different systems to administer and assess evaluations. While there are numerous published articles regarding these forms of evaluation, almost no literature exists that reflects the opinions of those actually completing the evaluations, ie, students. Explaining the purpose of evaluations and how they will be used, how to correctly complete evaluations, and the potential responsiveness of and receptivity of professors, as well as other factors, impact how students perceive and complete their evaluations. It is worthwhile to gather students' perspectives on evaluations as these assessments hold the potential to drive curricular change and faculty promotion. Considering students perspectives can help colleges and schools design and administer more effective evaluations, increasing the utility of these assessments.
\end{abstract}

Keywords: education, evaluation, academia

Throughout pharmacy school I was faced with a dilemma at the end of each semester: completing faculty and course evaluations. The dilemma did not arise from a lack of opinions about the courses or the professor(s) who taught them, but rather from my perception of these evaluations. I had been completing these types of evaluations since enrolling in undergraduate studies, and usually expressed the extremes of my opinions on them. If a professor had gone above and beyond in their teaching efforts or a course was particularly well organized, I took time to mention this and praise their efforts in the classroom, hoping that it might lead to the faculty member receiving an award or promotion. Alternatively, if I perceived a professor's instruction or course as being ineffective or lacking, I would offer constructive criticism on the evaluation form and express where changes could be instituted. This was all done in hopes that I was providing valuable opinions to the individual faculty member and whoever else might be reading the evaluation. It recently dawned on me that my practices surrounding and perceptions about evaluations were challenged during

Corresponding Author: Frank Romanelli, University of Kentucky, College of Pharmacy, 789 S. Limestone Rd., Lexington, KY 40536. Tel: 859-338-3911. Email: froma2@ uky.edu pharmacy school, especially since responding to them was required for course completion. Now that I have graduated, it is time to evaluate the evaluations.

There is a plurality of literature relating to the design and administration of evaluations. ${ }^{1-4}$ While many researchers correctly identify factors that impact the completion rate and quality of evaluations, such as requiring participation, time of year the evaluation is administered, and number of evaluations the student has to complete, several leave out important details that students often consider. One of the most important factors is that of the purpose and utilization of the responses provided on evaluations. Each semester, I and several classmates would question what the evaluations were actually being used for. Did student evaluations somehow contribute to faculty promotions or terminations? Were courses actually changed following receipt of constructive feedback provided in evaluations? These questions link directly with a student's willingness to complete evaluations. Evaluations are often lengthy and require significant time to complete. With this in mind, students' commitment to providing quality feedback on evaluations may be lacking if they do not comprehend the value in the process.

As a student I always wanted tangible examples of how evaluations were used. Pharmacy schools should find ways to showcase what curricular changes, faculty 


\section{American Journal of Pharmaceutical Education 2020; 84 (12) Article 8388.}

advancements, and course improvements resulted because of feedback gathered from evaluations. Examples of this could include explaining to students how a course instituted new material as a result of student evaluations, or how the course no longer requires a specific assignment because of recurrent themes identified in student evaluations. When this messaging is present, students are more apt to invest time in writing constructive and in-depth evaluations. I also often questioned who actually read the evaluations. Are evaluations being read only by professors, or does the department chair, administrative staff, and/or dean read them as well? Knowing this information might strengthen students' understanding of evaluations as well as their desire to complete them. Robust communication regarding the purpose of evaluations has to be present at all levels of the institution. Administrators must be willing to analyze and use evaluations in meaningful ways in order to garner an authentic commitment from both faculty members and students.

On almost every evaluation that I completed, I thought to myself, "Am I doing this correctly?" As mentioned previously, most of my classmates and I came into pharmacy school having already completed evaluations at undergraduate institutions. This prior experience, however, does not make students evaluation experts. Very few times across my educational journey was instruction provided on what valuable feedback looked like and how to construct it, especially in written form. While the importance of completing evaluations is often stressed throughout pharmacy school (eg, tied to course or degree completion, a factor in accreditation), very few times is the how of completing evaluations considered. Most of my classmates and I usually only expressed what our "favorite" or "least favorite" elements of the course or qualities of the instructor had been on evaluations. Seldom were recommendations made regarding how to continue excellent teaching or how to amend poor practices. While our shallow feedback may have been somewhat helpful for our professors, evaluations that include constructive criticism, thoughtful reflection, and documentation of specific teaching practices are more likely to provide useful insights. Poor completion rates and/or quality of evaluations may be related to a student's misconceptions about evaluations as well as linked to the previously mentioned factors, such as well-being, evaluation length, time of year, etc. Colleges of pharmacy (and ideally all institutions) must take time to educate students on how to provide effective feedback and evaluate what environments facilitate successful and insightful completion. As colleges look to hire or use curricular specialists, administrative staff, and pedagogists, the responsibility of teaching and facilitating evaluation completion should be formally assigned and the purpose and use of evaluations should be included in strategic plans. Additionally, students should have a designated person who they can consult regarding evaluations. When colleges and faculty members become intentional about evaluations, so will students.

Some academicians may claim that evaluations are simply "popularity contests" and that only the well-liked professors and courses receive evaluations and/or positive comments. After completing seven years of higher education, I can certainly see where this would be the case and have fallen victim to this myself. While popularity increases the chances of completion and positive remarks, it would also be disingenuous to completely discount the opinions and observations of learners. ${ }^{4}$ As others have aptly pointed out, asking a student to quantify how much they have learned across an entire semester is a difficult request at best. ${ }^{4}$ It would be more prudent to ask: What would increase the popularity of the course? When professors expressed empathy, vulnerability, compassion, or even humor, students such as myself were able to develop amiable perceptions of and connections with these professors. In turn, these were often the first professors that I and others would complete evaluations for simply based off of the principle that it is easy to construct responses of affirmation and praise rather than to write about negative experiences. While evaluations for these types of professors tend to be positive in nature, this can be explained by the fact that the positive qualities expressed by professors often open the door for honest, constructive feedback. It is much more than "popularity" alone that may convince students to complete evaluations and provide feedback, rather the drive may come from the qualities and practices of the individual in terms of nurturing and facilitating a desire for feedback. Through my experiences, the qualities that made a professor "likeable" also translated to effective teaching. It is easier to learn from a professor expressing the aforementioned qualities because of the positive learning environment created. The reverse can also hold true as well. If a professor expresses frustration, anger, and/or confusion, these instances are often remembered and factored into end-of-course evaluations. Does this mean that students expect professors to be perfect and never "mess up" in the classroom? This simply cannot and should not be the case. These types of attitudes and behaviors, however, must be recognized as ones that can hinder effective teaching as well as the completion and quality of evaluations.

Administrators and faculty members alike should not unilaterally and naively discount all elements of teaching and course evaluations. Rather, these instruments should be treated cautiously and with a critical eye. They might 


\section{American Journal of Pharmaceutical Education 2020; 84 (12) Article 8388.}

not measure exactly how much learning occurred in a classroom, but they may offer insight into faculty members who are able to transmit a passion for knowledge, generate enthusiasm for their subject matter, and instill in students a spark or desire to know more about a given subject matter or topic. The most thoughtful and descriptive evaluations I completed were for teachers who had the vulnerability to admit mistakes or shortcomings and an explicit drive to perform better. When professors included us on their instructional journey, we were able to engage with and evaluate them and their courses more honestly and critically. It is difficult to envision any student wanting to learn more about a topic or advance their knowledge of a subject following displeasing experiences with that course content. Rather than limiting their focus to their popularity among students, professors should strive to emulate characteristics that facilitate open, honest communication. This mindset will lead to not only completion of evaluations by students, but quality feedback, regardless of whether a professor is liked or not.

Faculty and course evaluations have long been the subject of extensive debate and academic research. While information gathered with these tools is often used as justification for faculty promotions and curricular change, it is vital to understand that no evaluative tool alone can completely and accurately assess and reflect the value of a faculty member or a course. Considering students' biases and fallacies sheds light on the limitations of evaluations. As I have committed time and effort to understanding my unconscious biases in recent years, I have discovered that these very biases could have been and were likely present in my responses on evaluations. I now wonder how student biases affect faculty and courses at all colleges of pharmacy employing student evaluations. This concern makes it important for colleges to invest time and resources into these insightful tools. Is it appropriate to apply the same assessment tools to a wide array of professors and courses? And should this be done without educating students on what is important to consider and express on as well as the purpose of assessments? Colleges must be willing to consider students' views, like the ones presented here, in order to understand and improve the assessment provided by evaluations. When this is done, evaluations can be combined with other proven methods of assessment to enhance and improve student learning.

\section{REFERENCES}

1. Medina MS, Smith WT, Kolluru S, et al. A review of strategies for designing, administering, and using student ratings of instruction. Am J Pharm Educ. 2019;83(5):Article 7177. DOI: 10.5688/ajpe7177.

2. Barnett CW, Matthews HW. Teaching evaluation practices in colleges and schools of pharmacy. Am J Pharm Educ. 2009;73(6): Article 103.

3. Carpenter SK, Witherby AE, Tauber SK. On students' (mis) judgements of learning and teaching effectiveness. J Appl Res Mem Cogn. 2020;9:137-151.

4. Oppenheimer DM, Hargis MB. If teaching evaluations don't measure learning, what do they? J Appl Res Mem Cogn. 20202;9: 170-174. 